\title{
UJI PENINGKATAN MUTU BATUBARA PERINGKAT RENDAH SUMATERA SELATAN
}

\author{
Hartiniati \\ Pusat Teknologi Pengembangan Sumberdaya Energi \\ BPPT Gedung II Lantai 22 JI MH Thamrin 8 Jakarta 10340 \\ E-mail: hartiniati@yahoo.com
}

\begin{abstract}
A study of coal upgrading by way of evaporative method using coal from South Sumatra is conducted. Preliminary inestigation on Upgrading of Brown Coal (UBC) process using Central and South Banko coals suggests that the process can be applied to both coals (called S-BK and C-BK) without any operational problem. It produces high quality-stable coals in the briquette form with a calorific value of more than $6,500 \mathrm{kcal} / \mathrm{kg}$. Moreover, its spontaneous combustion characteristic is also suppressed comparing to that conventional drying method. This is due to the addition of aspal (heavy oil) in the solution of kerosene, where the aspal then soaked in the micropore of to prevent reabsorption of water when put in the air.
\end{abstract}

Kata Kunci: upgrading brown coal, Banko coal, briket batubara, spontaneous combustion

\section{PENDAHULUAN}

Di beberapa sektor, seperti industri dan teknologi pembangkit tenaga listrik, kedudukan batubara sangat penting sebagai salah satu sumber energi alternatif yang tingkat penjualannya meningkat tiap tahun.

Sekitar $60 \%$ dari total sumberdaya batubara Indonesia berupa batubara muda atau lignite, yang potensinya mencapai 93,4 milyar ton (CDIEMR, 2008). Batubara ini bersifat mudah terbakar sendiri secara tiba-tiba sehingga harga penjualannya di pasaran sangat rendah dan tidak mudah menjualnya, juga menanganinya.

Berkaitan dengan hal tersebut, di akhir tahun 1970, pemerintah mulai merencanakan kebijakan energi baru dengan 4 (empat) elemen garis besar: intensifikasi, diversifikasi, konservasi dan indeksasi. Keempat elemen tersebut dimaksudkan untuk memaksimalkan pemanfaatan berbagai macam sumber daya energi agar ketergantungan pada minyak bumi dapat dikurangi sehingga pemakaiannya lebih efisien serta mendayagunakan energi tersebut secara tepat sasaran.

Pemerintah memiliki wewenang dalam penanganan batubara untuk mendayagunakannya secara besar-besaran untuk memenuhi kebutuhan energi dalam negeri. Disamping itu, pemerintah juga mengekspor batubara dengan nilai kalor yang tinggi jenis bituminuous dan sub-bituminuous.
Jepang adalah negara tujuan ekspor batubara terbesar dari Indonesia, disana, batubara (steam coal) digunakan sebagai bahan bakar di bidang industri maupun sebagai bahan bakar pembangkit listrik.

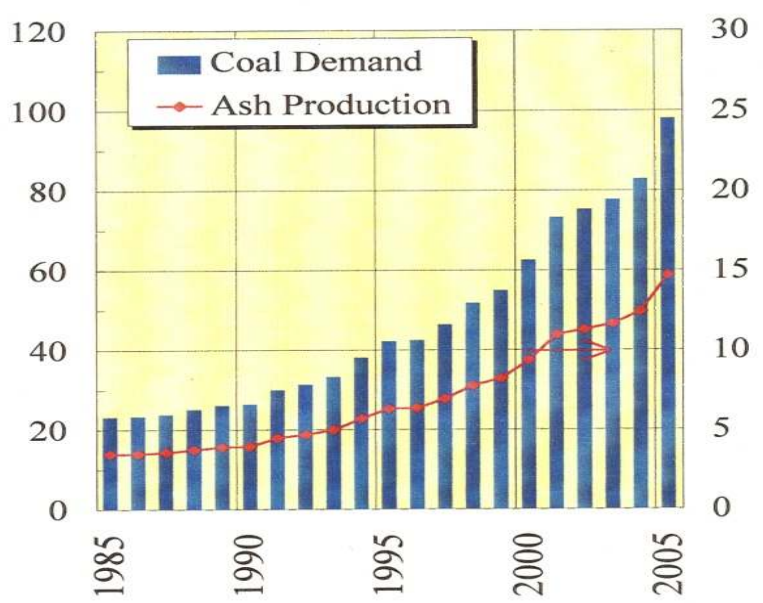

Gambar 1. Permintaan batubara dan produksi abunya di Jepang antara tahun 1985-2005 (Makino, 2006)

Pada Gambar 1 terlihat tingkat kebutuhan batubara di Jepang serta perkiraannya hingga tahun 2005 dan besarnya jumlah abu yang dihasilkan. Tingginya kebutuhan batubara menyebabkan terjadinya peningkatan jumlah abu 
yang menjadi masalah serius di Jepang. Mengingat area tanah Jepang relatif kecil, sehingga pemerintah Jepang harus menanganinya secara khusus dengan menekan laju penambahan produksi batubara. Untuk itu, pemerintah Jepang mengharuskan warganya menggunakan batubara yang mengandung sedikit abu karena Jepang telah mengeluarkan dana mencapai US\$ 50/ton hanya untuk menangani limbah abu.

Oleh karena itu, kedepannya batubara ramah lingkungan akan banyak mendominasi ekspor batubara dari Indonesia ke Jepang, kelebihan batubara ini adalah kandungan abu dan sulfur di dalamnya relatif kecil. Namun demikian, batubara ramah lingkungan yang berasal dari Indonesia ini kebanyakan berupa batubara muda dengan kandungan air yang tinggi, yaitu sekitar $50-60 \%$. Semakin banyak air yang terkandung di dalam batubara, semakin rendah kualitas batubara tersebut, sehingga tingkat penjualannya relatif rendah, baik di pasar internasional maupun domestik. Karena itu, dibutuhkan pengolahan batubara secara tepat untuk meningkatkan kualitas batubara agar permintaan pasar domestik dan internasional dapat terpenuhi.

Selama ini, batubara yang banyak diekspor oleh Indonesia hanya batubara yang memiliki kualitas tinggi. Sebelum menambang batubara kualitas tinggi,, terlebih dulu harus menambang batubara kualitas rendah. Hal tersebut dikarenakan posisi batubara kualitas tinggi berada dibawah batubara kualitas rendah. Batubara kualitas rendah yang berada diatasnya merupakan 'overburden' bagi batubara kualitas tinggi sehingga banyak batubara kualitas rendah yang ditambang. Untuk itu, para peneliti dituntut menciptakan dan mengembangkan sebuah teknologi alternatif yang dapat mengkonversi batubara kualitas rendah menjadi "exportable coal' tanpa harus mengeluarkan biaya yang mahal. Saat ini telah ditemukan teknologi yang dapat digunakan. Salah satunya adalah teknik upgrading atau yang lebih dikenal dengan teknologi Upgrading Batubara Muda (UBC).

Kerjasama yang sedang dilakukan oleh BPPT dengan Kobe-Steel, Jepang, serta beberapa perusahaan penambangan di Indonesia antara lain dari Sumatera Selatan, Kalimantan Selatan, dan Kalimantan Timur, yaitu dengan melakukan pengkajian awal terhadap penerapan teknologi tersebut untuk semua jenis batubara muda di Indonesia.

Dalam studi ini disajikan hasil penelitian peningkatan mutu (upgrading) batubara yang berasal dari 2 (dua) area pertambangan yang berbeda di Sumatera Selatan, yaitu Banko Selatan dan Banko Tengah (S-BK dan C-BK).
Pengujian ini dilakukan menggunakan autoclave (AC) sebagai alat uji di laboratorium skala kecil, selanjutnya untuk skala yang lebih besar digunakan unit kontinyu Bench Scale Unit (BSU) kapasitas $100 \mathrm{~kg}$ per jam.

\section{URAIAN SINGKAT TENTANG PROSES}

Batubara muda yang berkualitas rendah dapat diubah menjadi batubara bermutu tinggi dengan proses UBC, yaitu proses yang khusus dikembangkan untuk meningkatkan kualitas suatu batubara. Proses tersebut dikembangkan karena terinspirasi oleh proses slurry dewatering yaitu salah satu unit dari plant pencairan batubara muda yang prosesnya terdiri dari tiga unit: 1). Coal Slurry Making and De-watering, 2). Hydro-Liquefaction (+Inline Hydrotreating), dan 3). Solvent De-ashing (Hartiniati, 1999).

Kelebihan proses UBC bila dibandingkan dengan proses upgrading lainnya di seluruh dunia adalah proses UBC ini memiliki kondisi operasi yang jauh lebih 'mild' seperti yang ditunjukkan oleh Gambar 2, yaitu dioperasikan pada temperatur $140^{\circ} \mathrm{C}$ dan tekanan $350 \mathrm{kPa}$, sehingga selain tidak bersifat merusak struktur kimia batubara juga biaya yang dikeluarkan akan menjadi lebih rendah.

Proses UBC pada dasarnya dibagi menjadi 4 (empat) tahapan utama yaitu pembuatan bubur batubara (slurry making), pengeluaran kandungan air (slurry dewatering), pemisahan batubara dengan minyak (coal-oil separation), dan pengambilan minyak (oil recovery), (Deguchi, 1998).

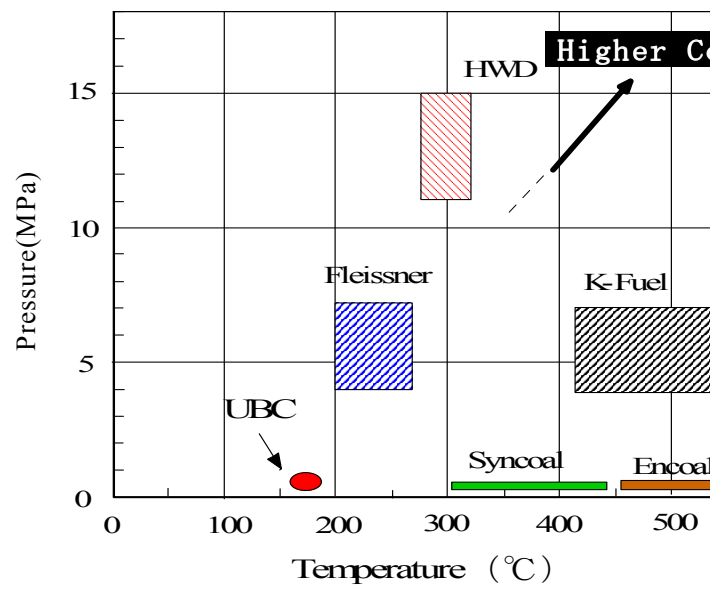

Gambar 2. Kondisi operasi dari beberapa proses upgrading batubara di seluruh dunia (Makino, 2006).

Selama proses UBC berlangsung, perlu dilakukan penambahan sejumlah kecil minyak berat untuk memperlancar berlangsungnya proses slurry dewatering. Air yang terkandung di 
dalam batubara dikeluarkan, selanjutnya minyak tersebut diabsorpsi secara selektif ke permukaan batubara dengan maksud mengubah kualitas permukaan batubara muda dari hidrofilik menjadi hidrofobik, sehingga didapatkan produk yang stabil, dalam kondisi ini biasanya zat perekat (binder) tidak perlu ditambahkan lagi. Penjelasan lebih detail mengenai proses UBC ini, dalam bentuk blok diagram dan aliran proses disajikan pada Gambar 3 dan Gambar 4.

\section{METODOLOGI PENELITIAN}

Pengujian dilakukan dengan melalui beberapa tahapan riset berikut:

Pertama, dilakukan pengujian dengan fasilitas autoclave yaitu pengumpulan data enjiniring dari fasilitas slurry dewatering agar diketahui kondisi optimum proses

Kedua, dilakukan pengujian dengan unit kontinyu BSU yaitu pengumpulan data enjiniring dari fasilitas slurry dewatering dan menghasilkan produk sampel yang diperlukan untuk pengujian kualitas produk UBC.

Ketiga, dilakukan pengujian dengan dengan fasilitas pengering fluidized bed untuk melaksanakan pengumpulan data tentang recovery (pengumpulan kembali) minyak yang digunakan dalam proses.

\subsection{Pengujian dengan Autoclave}

Dalam studi ini, digunakan autoclave 5 liter yang dilengkapi dengan keran pengontrol, kondensor dan bak penampung kondensat atau receiver. Mula-mula, batubara dengan ukuran partikel kurang dari $3 \mathrm{~mm}$ dipisahkan. Selanjutnya dimasukkan ke dalam autoclave bersama-sama dengan kerosin fraksi ringan dan aspal. Kemudian air yang terkandung di dalam batubara dikeluarkan dengan cara memanaskannya pada tekanan yang stabil dengan menggunakan pemanas listrik sambil terus diaduk.

Selanjutnya, di dalam kondensor dilakukan pendinginan terhadap uap air yang keluar dari batubara dan sebagian minyak yang terbawa, untuk memisahkan minyaknya dan menampungnya di dalam tangki penampung. Berdasarkan studi yang dilakukan dengan autoclave ini diperoleh informasi dasar mengenai karakteristik proses pemisahan air dari bubur batubara (slurry dewatering), serta fluiditas dari bahan baku dan slurry setelah proses dewatering.

\subsection{Pengujian dengan Bench Scale Unit (BSU-100 kg)}

Terdapat 3 (tiga) bagian proses pada fasilitas BSU, yaitu proses slurry dewatering, proses pemisahan minyak dan air, dan proses recovery, yaitu pengumpulan kembali minyak yang dipakai dalam proses. Luaran produk rata-rata yang dihasilkan adalah sebesar 100 kg per satu 'batch' pengujian. Total pengujian dengan UBC adalah 4 (empat) kali, dimana masing-masing 2 (dua) kali untuk penggunaan batubara S-BK dan C-BK.

Tahap pengoperasiannya dimulai dengan mempersiapkan batubara sebagai slurry yang dimasukkan ke dalam tangki berpengaduk yang diatur pada suhu ruang. Selanjutnya batubara tersebut dipompakan ke dalam kolom pemanas awal untuk dipanaskan. Kemudian dimasukkan ke dalam evaporator yang bekerja pada suhu $140^{\circ} \mathrm{C}$ dan tekanan $350 \mathrm{kPa}$. Dalam proses tersebut, pemanasan dilakukan dengan menggunakan uap air yang dimasukkan ke dalam shell dari pemanas. Uap air dan sebagian fraksi minyak ringan yang dihasilkan dikumpulkan ke dalam receiver melalui keran pengontrol tekanan dan kondensor.

Pengukuran temperatur dan jumlah uap yang digunakan dilakukan selama pemanasan awal dan ketika dewatering, hal tersebut ditujukan agar karakteristik pemindahan panasnya dapat diketahui serta untuk menghitung keseimbangan panasnya. Setelah itu, dilakukan pendinginan (menjadi cake) terhadap batubara slurry yang sudah tidak mengandung air, untuk selanjutnya dikeluarkan dan dimasukkan ke dalam vessel pada suhu kamar. Pemisahan batubara dengan minyaknya dilakukan dengan memasukkan 'cake' tersebut ke dalam alat pemisah sentrifugal dengan diameter $658 \mathrm{~mm}$ dan tinggi $295 \mathrm{~mm}$. Pada tahap akhir, cake yang sudah tidak mengandung minyak dikeringkan dalam pengering unggun terfluidisasi dengan diameter $565 \mathrm{~mm}$ dan tinggi $920 \mathrm{~mm}$ dengan menggunakan gas panas pada suhu $180^{\circ} \mathrm{C}$ [Deguchi, 1999].

\subsection{Pengujian Dengan Unit Pengering Unggun Terfluidisasi (PUT)}

Tujuan pengujian ini adalah untuk mendapatkan informasi dasar mengenai recovery minyak dari cake yang diperoleh berdasarkan hasil proses separasi batubara dengan minyak. Metode pengumpulan minyak lain yang dapat digunakan untuk plant selain dengan teknik PUT adalah dengan teknik steam tube dryer dan flush separation.

\subsection{Unit Pengering Unggun Terfluidisasi (PUT)}

Komponen unit PUT terdiri dari pengering unggun terfluidisasi dengan diameter bed 120 $\mathrm{mm}$ dan luasnya $0,0113 \mathrm{~m}^{2}$, pemanas gas, kondensor, siklon, dan tangki penampung atau receiver. Cake yang masih mengandung minyak 
dipanaskan di dalam bed dengan menggunakan nitrogen panas yang dialirkan dari bawah pengering supaya fluidisasi terjadi. Selama pengeringan berlangsung, sampel yang berada di dalam bed dikumpulkan sewaktu-waktu sambil terus memeriksa hasil pengeringan.

Selanjutnya, dilakukan pemisahan partikelpartikel halus terhadap siklon, sehingga minyak yang terevaporasi terkumpul kembali lewat kondensor. Pada kecepatan gas sebesar 0,17 $\mathrm{m} /$ detik dan suhu $135^{\circ} \mathrm{C}$ dan $190^{\circ} \mathrm{C}$ dilakukan pengujian menggunakan pengering unggun terfluida.

\section{HASIL PENELITIAN}

Pengamatan yang dilakukan terhadap semua unit peralatan yang digunakan pada BSU test selama berlangsungnya pengujian (empat run), menunjukkan bahwa hampir tidak terjadi masalah selama operasi, operasi berjalan dengan baik hingga diperoleh batubara tanpa kandungan air di dalamnya, dimana sebelumnya batubara tersebut mengandung $470 \mathrm{~kg}$ air.

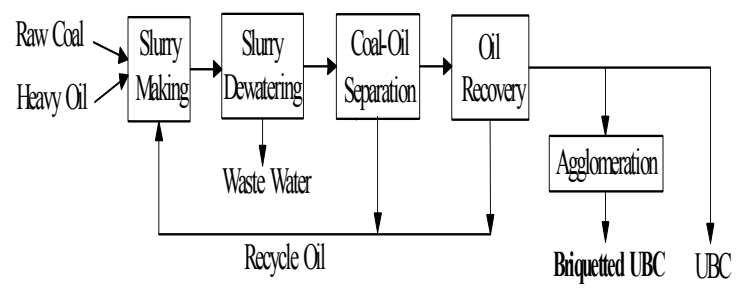

Gambar 3. Diagram alir blok dari proses UBC (Deguchi 1998, 1999)

Pada Gambar 3 ditunjukkan proses yang menjelaskan waktu operasi dengan temperatur slurry yang saling berkaitan dengan berat air dan minyak yang dapat dipisahkan dari batubara.

Kesimpulan yang dapat diperoleh dari pengujian dengan BSU adalah bahwa batubara S-BK dan C-BK ternyata memilki slurry dewatering dengan karakteristik yang sempurna. Ternyata, tidak ditemukan masalah sama sekali selama berlangsungnya proses UBC, sehingga proses ini dianggap yang paling sesuai untuk diterapkan pada kedua jenis batubara Sumatera Selatan tersebut. Proses pemisahan batubara dengan kandungan minyaknya serta proses recovery berlangsung lancar.

Dari analisa yang dilakukan terhadap pemindahan panas pada kolom evaporator, diperoleh informasi bahwa koefisien pemindahan panas yang terjadi sebesar $400 \mathrm{kkal} / \mathrm{m}^{2}$.jam. ${ }^{\circ} \mathrm{C}$. Sedangkan hasil yang ditunjukkan dari analisa terhadap limbah cair adalah bahwa limbah tersebut mengandung BOD dan COD masingmasing 132 161 ppm dan 28 38 ppm. Jumlah tersebut menunjukkan bahwa proses pemisahan minyak dengan air dari penggunaan teknologi UBC telah mencapai titik yang sempurna. Dengan kata lain, proses UBC ini dapat dimasukkan dalam kategori proses batubara bersih.

Berdasarkan pengamatan yang pernah dilakukan (TCLC, 1999), bahwa sangat memungkinkan untuk mengatur kondisi operasi dengan konsentrasi batubara yang tinggi yang dinyatakan sebagai rasio $\mathrm{O} / \mathrm{C}$ atau yang biasa disebutkan untuk rasio minyak terhadap batubara kering tanpa air dalam slurry, hal ini karena kenyataannya tidak ada masalah sama sekali di dalam pipa aliran slurry di dalam keseluruhan proses. Perkiraan yang didasarkan pada hasil beberapa pengujian menggunakan autoclave dan BSU, menunjukkan bahwa upgrading batubara S-BK dan C-BK dari Sumatera Selatan bisa diperoleh dengan rasio $\mathrm{O} / \mathrm{C}=1,2$. Dibandingkan dengan batubara Australia, misalnya yang mempunyai rasio 2,3 maka batubara S-BK dan C-BK tersebut dapat mempunyai ukuran unit upgrading yang lebih kecil dibandingkan dengan unit upgrading untuk batubara Australia dalam kapasitas yang sama. Hasil yang sangat baik juga ditunjukkan dari recovery fraksi minyak ringan (dalam unit pemisah) dengan solid, recovery minyak mencapai lebih dari 99\% dari neraca massa seluruh proses.

Pada Gambar 4 ditunjukkan hasil pengujian menggunakan Unit Pengering Terfluidisasi. Hasil percobaan menunjukkan bahwa tingginya temperatur gas sangat berpengaruh terhadap sedikitnya waktu yang dibutuhkan selama proses pengeringan. Proses pengumpulan minyak berlangsung selama 20 menit jika temperatur gas minyak tersebut adalah $190^{\circ} \mathrm{C}$. Cara pengujian seperti ini dapat dipakai untuk memperoleh informasi dasar dan data yang diperlukan untuk membuat desain konsep dari proses recovery

\subsection{Evaluasi Produk Hasil Proses Upgrading}

Pengujian produk proses upgrading dari unit BSU dilakukan melalui serangkaian kegiatan sebagai berikut:

> Analisa terhadap sifat-sifat produk baik yang berbentuk bubuk maupun briket

$>$ Pengujian terhadap karakteristik sifat mudah terbakar (spontaneous combustion) dari bubuk hasil proses upgrading.

$>$ Pengujian terhadap mutu briket bubuk batubara hasil proses upgrading

$>$ Pengujian terhadap kualitas CWM (Coal Water Mixture) dari bubuk batubara hasil proses upgrading 


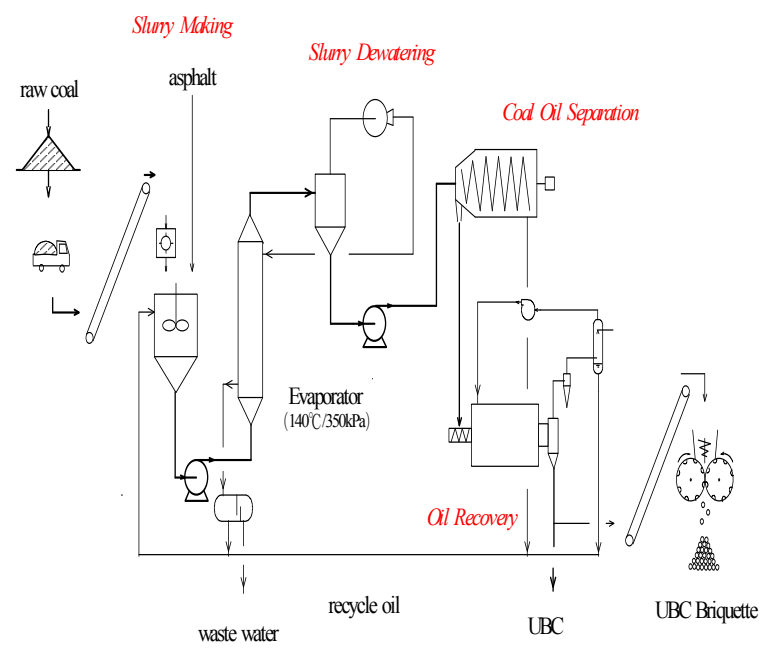

Gambar 4. Diagram alir dari proses UBC (Deguchi, 1998)

\subsection{Analisa Terhadap Sifat-sifat atau Karakteristik Produk}

Dalam Tabel 1 ditunjukkan karakteristik produk batubara (bubuk dan briket) dan juga karakteristik batubara asal (raw coal).

Pada batubara S-BK terjadi peningkatan lumayan besar terhadap nilai kalornya, yaitu dari $3.821 \mathrm{kkal} / \mathrm{kg}$ menjadi $6.260 \mathrm{kkal} / \mathrm{kg}$, peningkatan tersebut terjadi setelah melalui proses upgrading dan natural equilibrium moisture, dimana kandungan air di dalam batubara berkurang dari $43,4 \%$ menjadi $10,2 \%$. Kandungan air inherent atau equilibrium dari bubuk batubara juga turun dari $22 \%$ menjadi mendekati $0 \%$. Hal yang sama terjadi pada batubara C-BK, dimana nilai kalor batubara meningkat sangat tinggi, yaitu dari $4.540 \mathrm{kkal} / \mathrm{kg}$ menjadi $6.490 \mathrm{kkal} / \mathrm{kg}$ yang terjadi setelah air yang terkandung di dalam batubara berkurang dari $33,6 \%$ menjadi $9,8 \%$. Sama halnya dengan batubara S-BK, air inherent atau equilibrium yang terkandung di dalam bubuk batubara juga menurun.

Berdasarkan hal tersebut, sangat jelas berlangsungnya bahwa proses UBC dapat meningkatkan kualitas batubara dari 'brown coal' dengan nilai kalor yang rendah menjadi batubara dengan tingkat kualitas setara 'sub-bituminous coal' yang dicirikan dengan nilai kalor yang tinggi. Selain itu, mengacu pada sampel briket batubara Australia yang mengandung air inherent sebesar $3,2 \%$, dapat dipastikan bahwa air yang terkandung di dalam batubara S-BK dan C-BK adalah sekitar $4 \%$. Jika dibandingkan, tingkat porositas batubara Australia lebih besar daripada batubara Sumatera Selatan. Kesimpulan dari penjelasan tersebut adalah bahwa ada dua hal yang menyebabkan terjadinya pengurangan kandungan air pada batubara, yaitu adanya pengurangan jumlah porositas dan area permukaan kontak batubara dengan atmosfir karena dijadikan briket.

Berdasarkan perhitungan tersebut, diperkirakan nilai kalor briket batubara S-BK dan C-BK mencapai lebih dari 6,500 kkal/kg. Kecuali kandungan air, kandungan lain yang terdapat di dalam batubara sama sekali tidak berubah, seperti, kandungan abu, volatile matter dan elemen-elemen lainnya. Fenomena tersebut menunjukkan bahwa reaksi kimia tidak terjadi selama proses UBC berlangsung. Hal itu berarti selama proses, hanya terjadi reaksi fisika dan sebagian besar minyak yang ditambahkan selama berlangsungnya proses dapat diambil kembali (recovery).

Tabel 1. Data analisa batubara asal dan setelah diproses upgrading

\begin{tabular}{|l|l|r|r|r|r|}
\hline \multicolumn{2}{|c|}{ Batubara } & \multicolumn{2}{|c|}{ C-BK } & \multicolumn{2}{c|}{ S-BK } \\
\cline { 3 - 6 } \multicolumn{2}{|c|}{} & $\begin{array}{l}\text { Raw } \\
\text { Coal }\end{array}$ & UBC & $\begin{array}{l}\text { Raw } \\
\text { Coal }\end{array}$ & UBC \\
\hline Kandungan air & $\%$ ar & 33.6 & $\mathbf{9 . 8}$ & 43.4 & $\mathbf{1 0 . 2}$ \\
\hline Air Inherent & $\%$ & 20.7 & ---- & 22.0 & ---- \\
\hline Air briket & $\%$ & & & & $\mathbf{5 , 0}$ \\
\hline Abu & $\%$ db & 2.5 & $\mathbf{2 . 7}$ & 4.0 & $\mathbf{4 . 0}$ \\
\hline Zat Terbang & $\% \mathrm{db}$ & 51.2 & $\mathbf{5 2 . 5}$ & 48.4 & $\mathbf{5 0 . 6}$ \\
\hline Karbon Tetap & $\% \mathrm{db}$ & 46.3 & $\mathbf{4 4 . 8}$ & 47.6 & $\mathbf{4 5 . 4}$ \\
\hline Total sulfur & - & 0.48 & $\mathbf{0 . 4 8}$ & 0.31 & $\mathbf{0 . 3 4}$ \\
\hline Energi Spesifik & & & & & \\
\hline Kalori & $\begin{array}{l}\mathrm{kcal} / \\
\mathrm{kg}\end{array}$ & 4540 & $\mathbf{6 4 9 0}$ & 3821 & $\mathbf{6 2 6 0}$ \\
\hline (Briket) & $\begin{array}{l}\mathrm{kcal} / \\
\mathrm{kg}\end{array}$ & ------ & & ------ & $\mathbf{6 5 3 0}$ \\
\hline
\end{tabular}

\subsection{Investigasi Terhadap Sifat Mudah Terbakar (Spontaneous Combustion)}

Sebagian kecil minyak dan aspal yang ditambahkan ke dalam proses pembuatan slurry batubara pada tahap awal proses upgrading diabsorpsi ke dalam pori-pori permukaan batubara yang sudah tidak mengandung air. Hal tersebut membuat sifat mudah terbakar batubara asal (raw coal) menurun seiring dengan terjadinya penurunan area kontak permukaan batubara dengan udara. Kebenaran teori ini dibuktikan dengan menguji spontaneous combustion dari batubara S-BK dan C-BK yang dilakukan di laboratorium.

Prinsipnya, kondisi atmosfir disekitar penumpukan dan cara penumpukannya mempengaruhi sifat mudah terbakar batubara. Oleh karena itu, untuk menguji sifat tersebut perlu dilakukan penumpukan sejumlah sampel dalam jumlah yang signifikan di tempat yang terbuka. Sulitnya menyiapkan sampel dalam jumlah yang sangat besar menyebabkan evaluasi harus dilakukan dengan menggunakan fasilitas pengujian spontaneous combustion skala kecil atau skala laboratorium tipe SIT-1 yang pada 
penelitian ini menggunakan produk Shimadzu. Sebanyak 1 gram sampel batubara asal (raw coal) dimasukkan ke dalam oven adiabatik dengan temperatur di dalamnya sebesar $85^{\circ} \mathrm{C}$ hingga $100^{\circ} \mathrm{C}$, dimana terjadi kontak dengan udara panas yang mengalir pada temperatur yang sama dengan temperatur di dalam oven, selanjutnya temperatur sampel diukur.

Hasil test terhadap spontaneous combustion ini ditunjukkan pada grafik Gambar 5.

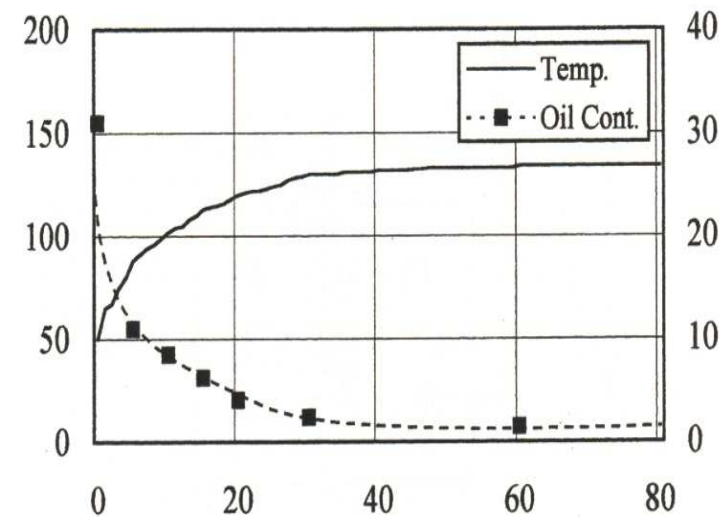

Gambar 5. Hasil test terhadap spontaneous combustion

Penelitian yang dilakukan di laboratorium menunjukkan bahwa setelah beberapa jam proses berlangsung, terjadi kenaikan temperatur akibat penambahan panas karena berlangsungnya proses pengeringan batubara, dan sesaat kemudian terjadi pembakaran sampel yang ditandai dengan adanya api. Namun ternyata pada penelitian yang sama, meskipun pemanasan telah berlangsung selama 96 jam, bahkan hingga proses upgrading telah selesai, sampel produk upgrading belum terbakar. Hal tersebut membuktikan bahwa proses upgrading telah membuat sifat mudah terbakar batubara berkurang atau dapat ditekan.

\subsection{Pengujian Terhadap Keandalan Briket Batubara dari Proses UBC}

Alat yang digunakan untuk membuat briket batubara disebut unit pembriketan double roll. Briket dihasilkan dengan menempatkan briket batubara dalam suatu tempat yang tekanan di dalamnya telah diatur.

Berdasarkan pengujian, diketahui bahwa briket dapat dihasilkan dari batubara S-BK dan C-BK tanpa penambahan zat perekat (binder).

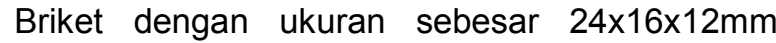
dapat dibuat dengan menggunakan mesin briket double roll yang berukuran besar pada temperatur sebesar $150-160^{\circ} \mathrm{C}$ tanpa menggunakan perekat.
Jika kondisi test diatur dengan sangat baik, maka akan dihasilkan briket dengan kerapatan lebih dari 1,2 gr/cc dengan kekuatan kompresi diatas $20 \mathrm{~kg}$. Akan tetapi, belum ditemukan nilai pasti untuk kondisi optimum dari proses pembriketan tersebut dan belum ada investigasi lebih lanjut pada penelitian ini.

\subsection{Pengujian Kualitas Coal Water Mixture (CWM) dari Bubuk Batubara Produk Upgrading}

Dalam penelitian ini juga dibahas mengenai pengujian sifat-sifat CWM dari batubara produk Upgrading. Pembuatan CWM dilakukan dengan mencampurkan bubuk batubara yang dihasilkan dari proses upgrading dengan air dan PSS (polystyrenesulfonate, sebagai surfaktan) yang dimasukkan ke dalam suatu ball mill. Selanjutnya dilakukan pengukuran konsentrasi batubara dalam CWM, seperti yang terlihat pada Gambar 6. Dalam hal ini, besarnya konsentrasi batubara dalam CWM bisa mencapai sekitar 63 berat\%.

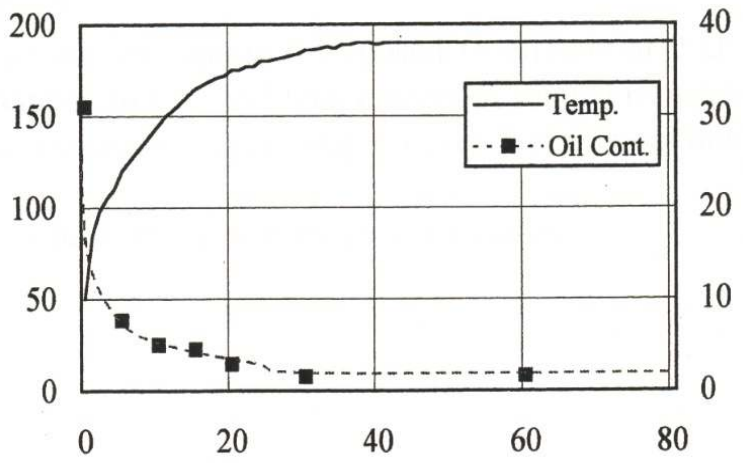

Gambar 6. Konsentrasi batubara dalam CWM

\section{KESIMPULAN}

Kesimpulan hasil evaluasi seluruh unjuk kerja proses upgrading batubara peringkat rendah (UBC), secara umum adalah sebagai berikut.

Hasil pengujian batubara S-BK dan C-BK yang berasal dari Sumatera Selatan dengan proses upgrading menunjukkan bahwa batubara tersebut sangat tepat untuk digunakan dalam percobaan tersebut, alasannya yaitu:

- Batubara tersebut memiliki daya operasi yang relatif stabil ketika pengujian dilakukan dengan manggunakan BSU pada unjuk kerja sempurna.

- Tingginya konsentrasi slurry pada bagian 'slurry dewatering' berdampak positif pada segi keekonomian proses.

- Tingkat kinerja yang bagus pada proses pemisahan minyak ringan dengan recovery pada bagian separasi dan 'oil recovery'. 
Berdasarkan pengujian kemudian diketahui bahwa produk upgrading (UBC) dari batubara SBK dan C-BK memiliki nilai kalor yang tinggi dengan kualitas solid yang baik.

Kandungan air total usai proses upgrading (UBC) dan setelah mencapai kondisi natural equilibrium moisture, pada batubara S-BK dan CBK masing-masing sebesar $10,2 \%$ dan $9,8 \%$, dengan nilai kalor masing-masing sebesar 6.490 $\mathrm{kkal} / \mathrm{kg}$ dan $6.260 \mathrm{kkal} / \mathrm{kg}$.

Pengamatan yang dilakukan menunjukkan bahwa batubara tidak mengalami perubahan sifat fisika, volatile matter, abu dan sulfur yang terkandung di dalamnya tetap sama, hal tersebut karena pada proses ini hanya menghilangkan air yang terkandung di dalam batubara.

Untuk menghilangkan atau memperkecil sifat mudah terbakar dari batubara muda (termasuk batubara S-BK dan C-BK) dilakukan pemrosesan batubara dalam unit proses upgrading (UBC).

Produk upgraded coal dapat dibuat briket dengan sempurna tanpa penambahan zat perekat

\section{DAFTAR PUSTAKA}

CDIEMR, 2008. Handbook of Energy and Economic Statistics of Indonesia 2008, Center for Data and Information on Energy and Mineral Resources, Ministry of Energy and Mineral Resources, Jakarta

Deguchi, Tetsuya, 1998. Proposal of UBC Process for Low Rank Coal Upgrading. Kobesteel, Ltd, Japan. Unpublished

Deguchi, Tetsuya, 1999. Report on Applicability of UBC Process for South Sumatera Coal. Internal Report-BPPT. Unpublished.

Hartiniati, 1999. Pencairan Batubara Banko, Internal Report-BPPT, Jakarta

Makino, Eiichiro, 2006. The Application of Malam Coal on UBC process. Minemouth UBC-IPP. Sojitz, Japan. Unpublished

TCLC, 1999. Application for BCL Process, Training Material. TCLC. Japan. Unpublished. 